\title{
The CT guided transoral approach: A biopsy technique for a poorly differentiated chordoma in a 5 year old
}

\author{
Robert D'Ortenzio ${ }^{1}$, Stefano Tolhurst ${ }^{1}$, Melissa Harvey ${ }^{2}$, Ravi Ghag ${ }^{3}$, Manraj KS Heran ${ }^{4 *}$ \\ 1. Department of Radiology, Vancouver General Hospital, Vancouver, Canada \\ 2. Department of Pediatrics, BC Children's Hospital, Vancouver, Canada \\ 3. Department of Orthopaedics, BC Children's Hospital, Vancouver, Canada \\ 4. Department of Radiology, BC Children's Hospital, Vancouver, Canada
}

* Correspondence: Dr. Manraj K.S. Heran, BC Children's Hospital, 4500 Oak St, Vancouver, BC, V6H 3N1, Canada (入manraj.heran@vch.ca)

Radiology Case. 2021 Mar; 15(3):1-8 :: $\quad$ DOI: 10.3941/jrcr.v15i3.4208

\begin{abstract}
Mass lesions presenting at the craniocervical junction often present a unique challenge due to the complex anatomic arrangement limiting access for tissue diagnosis. The transoral approach has predominantly been used for percutaneous vertebroplasty of high cervical vertebrae with limited literature describing image guided biopsy for bony lesions in this region in the pediatric patient. We describe a technique of computed tomography guided transoral biopsy of a poorly differentiated chordoma located at the $\mathrm{C} 1-\mathrm{C} 2$ level in a 5-year-old child, and review this diagnosis.
\end{abstract}

\section{CASE REPORT}

\section{CASE REPORT}

A 5-year-old female presented to hospital with a 12month history of chronic neck stiffness and pain waking her up from sleep. She was previously healthy with unremarkable birth and past medical histories. Her initial physical examination yielded neck stiffness and pain, most aggravated by cervical extension. There were no neurological deficits. Initial cervical spine radiographs were reported as showing no abnormality.

Her ongoing pain and intractable neck stiffness prompted further investigation. MRI and CT revealed a soft-tissue mass extending from the clivus to the body of $\mathrm{C} 2$. It was located mainly to the right and midline between the odontoid process and the medial aspect of the anterior arch of $\mathrm{C} 1$ (Figure 1).
The lesion was poorly characterized on magnetic resonance imaging (MRI). It was infiltrative, non-enhancing, uniform intermediate to low signal intensity on $\mathrm{T} 1$ and $\mathrm{T} 2$ weighted imaging, and caused localized bony erosion/destruction of the clival tip, right aspect of the odontoid process, and the body of $\mathrm{C} 2$. There was elevation of the tectorial membrane, but no extension through the dura intracranially, and no compression of the spinal cord or adjacent brainstem. A definitive diagnosis could not be made on cross sectional imaging.

Need for biopsy was discussed during multidisciplinary tumor board including the clinical oncology, spine surgery and interventional radiology (IR) services. The location of the lesion and its proximity to the dura meant that an open biopsy would be associated with high morbidity and consensus decision was for percutaneous CT guided biopsy. 
After obtaining informed consent from the family, the patient was intubated, given a general anesthetic and placed supine on the CT gantry. Pre-procedure blood work demonstrated a normal coagulation profile and hemoglobin (INR: 1.0, PTT: $31, \mathrm{HgB} 13.1 \mathrm{~g} / \mathrm{dL}$ ). The spine surgical team was in house during the procedure and on immediate call if any complications were to occur such as bleeding. The patient received periprocedural antibiotics. Preliminary CT was then obtained of the upper cervical region and skull base to plan the approach to the lesion. The patient's head was positioned to allow for optimal visualization within the requirements of needle trajectory for successful biopsy. A tongue depressor and elastic tie around the mandible and mouth aided in optimizing oral aperture.

A 4-French vascular sheath $\left(\right.$ Pinnacle $^{\circledR} ;$ Terumo, Somerset, NJ, USA) was advanced through a plastic straw and positioned in the mouth with the tip indenting the soft tissue of the oropharynx at the C1-2 level, allowing for stable positioning at the target level. The valve had been cut off, and the advancement of the sheath was aided by use of its coaxial dilator. This sheath had been cut to match the length of the coaxial biopsy system which was to be used. An 18-gauge 9 $\mathrm{cm}$ long semiautomatic side-cut needle with a $2 \mathrm{~cm}$ throw length (Quick Core ${ }^{\circledR}$; Cook Medical, Bloomington, IN, USA) biopsy system was then advanced in a coaxial fashion through the sheath (Figure 2 and 3).

Under CT fluoroscopic guidance, the $2 \mathrm{~cm}$ throw of the core biopsy system was advanced, with the pass made immediately adjacent to the right aspect of the odontoid, between the lateral mass of $\mathrm{C} 1$ and the odontoid. Two biopsies were obtained, resulting in adequate tissue samples.

The patient's head position was then slightly flexed from its original extended position and the 4-French sheath with the plastic cover guiding system was repositioned to allow for appropriate access to biopsy superior to the anterior arch of C1. Again, CT fluoroscopic guidance and careful positioning were used to ensure the needle tip did not transgress the dura. Three additional biopsies were obtained from this position.

There were no post procedure complications and the patient tolerated the procedure well. Specifically, there was no infection, bleeding, uncontrolled pain or dysphagia. Further, there were no neurological signs or symptoms. She was admitted overnight for observation and discharged home the following day.

The initial pathology was reported as indeterminate, favoring an epithelioid sarcoma variant or a low-grade spindle cell tumor. Due to this uncertainty, a second CT-guided transoral biopsy was performed using similar technique. However, upon repeat review of the original biopsy tissue using brachyury as an immunohistochemical stain, a final diagnosis of an epithelioid malignancy consistent with poorly differentiated chordoma was made. Surgical resection was not technically feasible, and the patient went on to receive chemotherapy. Since initiation of therapy, the patient unfortunately developed lung metastases and has since passed away.

\section{DISCUSSION}

\section{Etiology \& Demographics:}

Chordoma, a neoplasm arising from primitive notochordal remnants, is a rare disease entity with annual incidence of 0.8 per 100,000 with a mean age of diagnosis at 50 - 60 years old and is slightly more common in males. Chordomas are rare in the pediatric population, encompassing less than 5\% of chordoma diagnoses. Chordomas are associated with high morbidity and mortality with mean survival of approximately 6 years $[1,2]$. The poorly differentiated chordoma is a newly recognized molecularly distinct subtype first described in 2016 with true incidence and demographics unknown[3]. Literature is limited to case reports and short case series. The poorly differentiated subtype tends to have higher incidence in pediatric patients with a predilection for involvement of the skull base or cervical spine [6]. Given its novelty and histologic characteristics, pathologic diagnosis is often difficult. Poorly differentiated chordoma may not show a chondroid type matrix unlike it's classical variant and demonstrates positive $\mathrm{T}$ brachyury and cytokeratin immunohistochemical staining [4]. Positive brachyury staining was the differentiating factor that allowed an accurate final diagnosis of poorly differentiated chordoma rather than epithelioid sarcoma for our patient.

\section{Clinical \& Imaging findings:}

MRI is the primary imaging modality for characterizing chordoma, including local tissue involvement, proximity to adjacent critical neurovascular structures. On T1-images, typical chordomas classically are iso or hypointense. T1 hyperintensity may be related to intra-lesional hemorrhage or cyst formation. On T2-weighted images, chordomas are typically hyperintense with a lobulated appearance characterized by multiple hypointense septae. The majority will demonstrate marked heterogeneous enhancement post gadolinium, with a honeycomb appearance of septa [5].

On CT, the majority of chordomas are often heterogeneous in their attenuation characteristics due to interspersing of tumor tissue (isoattenuating) and myxoid cyst or necrotic degeneration (hypoattenuating). Hyperattenuation may correspond to bony sequestration from destruction of bone rather than tumoral calcification [5]. These classical CT and MR imaging features were not present in our patient, as no significant enhancement was demonstrated on MRI. Imaging characteristics specific to the poorly differentiated subtype have not been previously described in a pediatric patient.

There has been growing popularity of the transoral approach in adult interventional radiology; however, its use was predominantly for performing vertebroplasty of lytic bone lesions as well as a few cases of fluoroscopic-guided biopsy $[6,7,8]$. These demonstrated that the transoral approach is a more direct approach to lesions at the craniocervical junction, away from important vessels and nerves, with the authors emphasizing their absence of complications, especially infection. Complication rates described in case reports are low but included cerebrospinal fluid leak, meningitis, pharyngeal infection, dysphagia and velopharyngeal insufficiency [4]. 
The technique employed in our patient demonstrates a variation in coaxial guidance, with use of a vascular sheath and its dilator to access through aerated soft tissue planes in a safe manner, thereby allowing for positioning of the biopsy cannula itself. Removal of the sheath's valve and cutting the sheath to match the length of the coaxial biopsy cannula, allows it to be used as an atraumatic access system while also avoiding streak artifact which would occur if conventional metallic coaxial guiding needles are used. Awareness of this variation in technique may be useful in selected situations where optimal visualization of the target structure is required.

\section{Treatment \& Prognosis:}

The poorly differentiated chordoma appears to exhibit more aggressive features with worse prognosis and decreased survival time compared to conventional chordoma. The malignancy is locally aggressive and tends to metastasize earlier than the classical chordoma [2]. Early diagnosis and treatment are essential to maximize the patient's chance for recovery. Treatment standards are not established in literature.

\section{Differential Diagnosis:}

\section{Classical Chordoma}

Classical chordoma is a rare malignancy arising from bone most often seen in adults, usually at the sacrum or craniocervical junction. The lesion is not well characterized on radiographs. On CT, its appearance is usually an expansile, well circumscribed lytic lesion which may have margin of sclerosis and soft tissue component centrally. Sequestered bone fragments are often seen centrally. On MRI, chordomas demonstrate heterogenous T1 hypointensity and often a characteristic "honeycomb" appearance on T2, with high T2 signal and interspersed thin linear septae of low T2 signal due myxoid composition. Enhancement pattern is variable on CT and MRI [9]. Avid enhancement on MRI may be associated with poor prognosis [10].

\section{Benign notochordal cell tumors}

These lesions are often asymptomatic and occult on imaging. The distribution is similar to chordomas, most often at the skull base or sacrum. Benign notochordal cell tumours are pathologically similar to classical chordomas and therefore can sometimes present a diagnostic challenge [11]. On CT, these often present as a sclerotic lesion without aggressive features or soft tissue component. Unlike our poorly differentiated chordoma case, low T1 and high T2 signal is often seen on MRI. No enhancement is demonstrated on CT or MRI [12].

\section{Ecchordosis physaliphora}

A benign, congenital usually asymptomatic hamartomatous tumour usually retroclival in location which arise from notochord remnants. This is a subtype of benign notochordal cell tumours., generally not well characterized on radiographs or CT. This lesion may be seen as a well circumscribed lytic lesion in the clivus on CT bone reformats. On MRI, the lesion demonstrates low T1 and high T2 signal with variable enhancement pattern. A stalk like connection to the clivus is characteristic although infrequently seen [13].

\section{Chondrosarcoma}

Chondrosarcoma is a relatively common aggressive osseous malignancy most often seen in adults. On imaging, they often demonstrated is the characteristic "ring and arcs" mineralization centrally in keeping with chondroid matrix. Less than $10 \%$ of chondrosarcomas occur in the spine. On radiographs and $\mathrm{CT}$, a large aggressive mass with cortical breach, soft tissue and endosteal scalloping is frequently demonstrated. On MRI, there is heterogenous low T1 and regions of iso-to-high T2 signal seen. Most chondrosarcomas demonstrate heterogenous enhancement both on CT and MRI [14].

\section{Metastases}

Osseous metastasis is a primary differential consideration in the adult population. In children, central nervous and haematologic malignancies, as well as osteosarcoma are most common to cause bony metastasis [15]. Spine metastases are not well characterized on radiographs. Osseous metastasis can have a wide range of appearances on CT and MRI with both lytic and sclerotic appearances and variable enhancement characteristics.

\section{TEACHING POINT}

Poorly differentiated chordoma should be included in the differential diagnosis for a pediatric patient presenting with a cervical mass, and it may not have classical imaging features seen with conventional chordoma. CT guided transoral biopsy may provide a less invasive method for craniocervical masses.

\section{REFERENCES}

1. Carbó E, Riquelme Ó, García A, González JL. Vertebroplasty in a 10-year-old boy with Gorham-Stout syndrome. Eur Spine J. 2015;24:590-593. PMID: 25586760

2. Shih AR, Cote GM, Chebib I, et al. Clinicopathologic characteristics of poorly differentiated chordoma. Mod Pathol. Published online 2018:1237-1245. PMID: 29483606

3. Hasselblatt M, Thomas C, Hovestadt V, et al. Poorly differentiated chordoma with SMARCB1/INI1 loss: a distinct molecular entity with dismal prognosis. Acta Neuropathol. 2016;132(1):149-151. PMID: 27067307

4. Dlouhy BJ, Dahdaleh NS, Menezes AH, MD. Evolution of transoral approaches, endoscopic endonasal approaches, and reduction strategies for treatment of craniovertebral junction pathology: a treatment algorithm update. Neurosurg Focus FOC. 2015;38(4):E8. PMID: 25828502

5. Beccaria K, Sainte-Rose C, Zerah M, Puget S. Paediatric Chordomas. Orphanet J Rare Dis. 2015;10(1):116. PMID: 26391590

6. Reddy AS, DiNobile D, Ortega JE PN. Transoral Approach to CT-Guided C2 Interventions. Pain Physician. 2009;12:253258. PMID: 19165307 
7. Tong FC, Cloft HJ, Joseph GJ, Rodts GR, Dion JE. Transoral Approach to Cervical Vertebroplasty for Multiple Myeloma. Am J Roentgenol. 2000;175(5):1322-1324. PMID: 11044032

8. Gabrillargues $\mathrm{J}$ MJ. Interventional radiology: transoral approach to C2. J Radiol. 2008;89(2):245-249. PMID: 18354355

9. Erdem E, Angtuaco EC, Van Hemert R, Park JS, Al-Mefty O. Comprehensive Review of Intracranial Chordoma. RadioGraphics. 2003;23(4):995-1009. PMID: 12853676

10. Lin E, Scognamiglio T, Zhao Y, Schwartz TH, Phillips CD. Prognostic Implications of Gadolinium Enhancement of Skull Base Chordomas. Am J Neuroradiol. 2018;39(8):1509 LP - 1514. PMID: 29903925

11. Kreshak J, Larousserie F, Picci P, et al. Difficulty distinguishing benign notochordal cell tumor from chordoma further suggests a link between them. Cancer Imaging. 2014;14(1):4. PMID: 25609192

12. Nishiguchi $\mathrm{T}$, Mochizuki $\mathrm{K}$, Ohsawa $\mathrm{M}$, et al. Differentiating Benign Notochordal Cell Tumors From Chordomas: Radiographic Features on MRI, CT, and Tomography. Am J Roentgenol. 2011;196(3):644-650. PMID: 21343509

13. Mehnert F, Beschorner R, Küker W, Hahn U, Nägele T. Retroclival Ecchordosis Physaliphora: MR Imaging and Review of the Literature. Am $\mathbf{J}$ Neuroradiol. 2004;25(10):1851 LP - 1855. PMID: 15569763

14. Murphey MD, Walker EA, Wilson AJ, Kransdorf MJ, Temple HT, Gannon FH. From the Archives of the AFIP. RadioGraphics. 2003;23(5):1245-1278. PMID: 12975513

15. Hernandez RK, Maegbaek ML, Liede A, Sørensen HT, Ehrenstein V. Bone Metastases, Skeletal-related Events, and Survival Among Children With Cancer in Denmark. J Pediatr Hematol Oncol. 2014;36(7):528-533. PMID: 24390452

16. Fox MW, Onofrio BM. The natural history and management of symptomatic and asymptomatic vertebral hemangiomas. J Neurosurg. 1993;78(1):36-45. PMID: 8416240

17. Jaber OI, Ashhab M Al. Metastatic poorly differentiated chordoma: the eyes do not see what the mind does not know. Autops case reports. 2019;9(4):e2019120- 


\section{FIGURES}

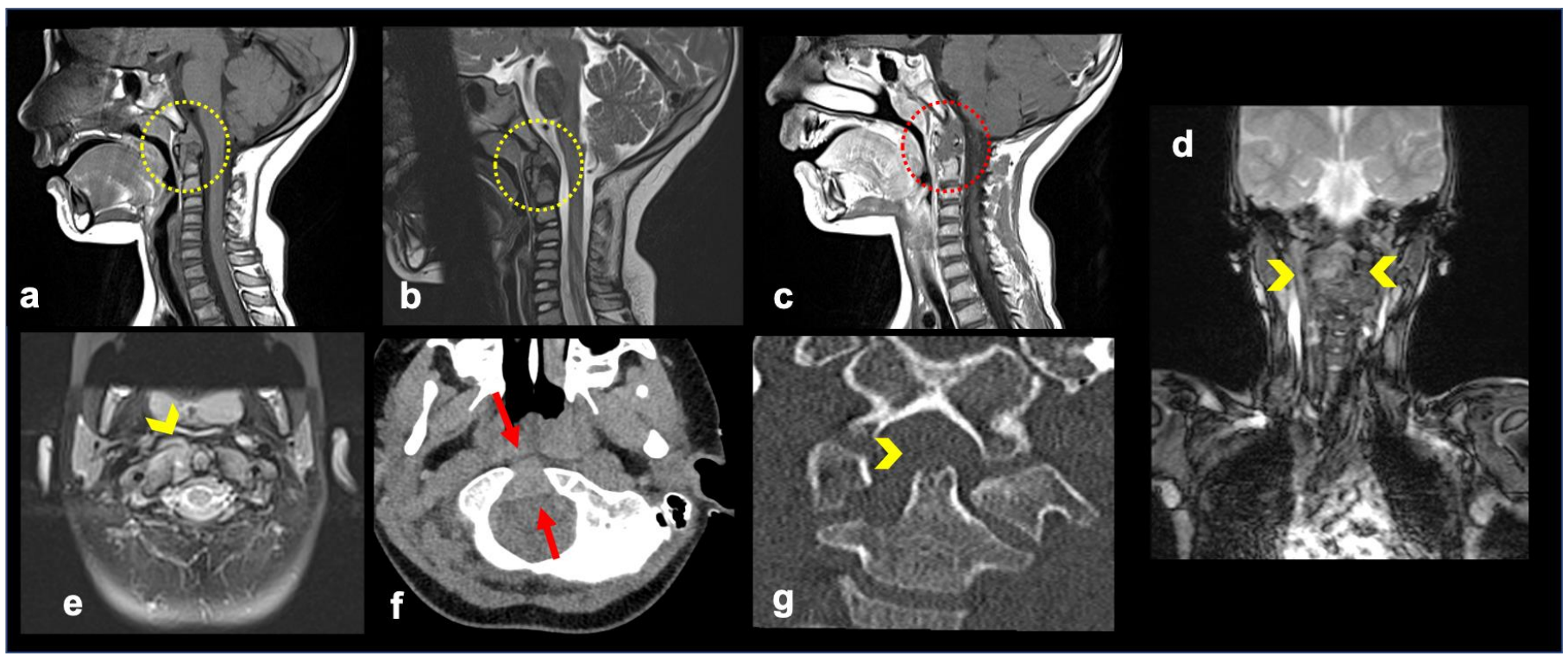

Figure 1: 5 year old female with poorly differentiated chordoma.

FINDINGS: MRI (1(a) - 1(d)) and non-contrast CT (1(f) and 1(g)) demonstrates a poorly differed chordoma centered at the odontoid and right lateral mass of $\mathrm{C} 2$ in a 5 years old female patient. (a) Sagittal MRI TSE T1 and (b) T2 weighted images demonstrate an infiltrating soft tissue mass centered at C1-C2 with lifting of the tectorium (yellow circle). There is no significant mass effect or signal changes at the spinal cord or medulla. (c) Sagittal T1 MRI images post gadolinium injection demonstrate no appreciable enhancement (red circle). (d) coronal and (e) axial, T2 weighted images demonstrate the ill-defined soft tissue mass at extending to the right lateral mass of $\mathrm{C} 2$ (yellow arrowheads). (f) (red arrows) axial unenhanced CT again demonstrates the soft tissue mass at $\mathrm{C} 1 \mathrm{~g}) \mathrm{CT}$ coronal bone reformats show associated bony erosion at the tip of the odontoid.

TECHNIQUE: (A - E) Siemens MRI scanner. Magnetic strength $=1.5$ Tesla. A: T1W fat sat sagittal. TR $=600 \mathrm{~ms}$ TE $=10 \mathrm{~ms}$. Slice thickness $=3 \mathrm{~mm}$. B: T2W TSE RESTORE sagittal. TR $=2600 \mathrm{~ms}$ TE $=118 \mathrm{~ms}$. Slice thickness $=3 \mathrm{~mm}$. C: Intravenous Gadovist $1.85 \mathrm{ml}$ was administered. T1W post-contrast saggital TR $=600 \mathrm{~ms}$ TE $=11 \mathrm{~ms}$. Slice thickness $=3 \mathrm{~mm}$. D: T2W fat sat coronal True-FSIP. TR $=5.2 \mathrm{~ms}$ TE $=2.6 \mathrm{~ms}$. Slice thickness $=5 \mathrm{~mm}$. E: T2W TSE fat sat axial. TR $=5010 \mathrm{~ms}$ TE $=108 \mathrm{~ms}$. Slice thickness $=4 \mathrm{~mm}$.

F, G Siemens CT non-contrast SOMATOM Definition FLASH. C: Slice thickness $=1 \mathrm{~mm} . \mathrm{kVp}=100$, Tube current $=60 \mathrm{~mA}$. Convolution Kernel: soft tissue I31s/2. D: Slice thickness $=1 \mathrm{~mm} . \mathrm{kVp}=100$, Tube current $=58 \mathrm{~mA}$. Convolution Kernel: bone $\mathrm{I} 70 \mathrm{~h} / 2$. 


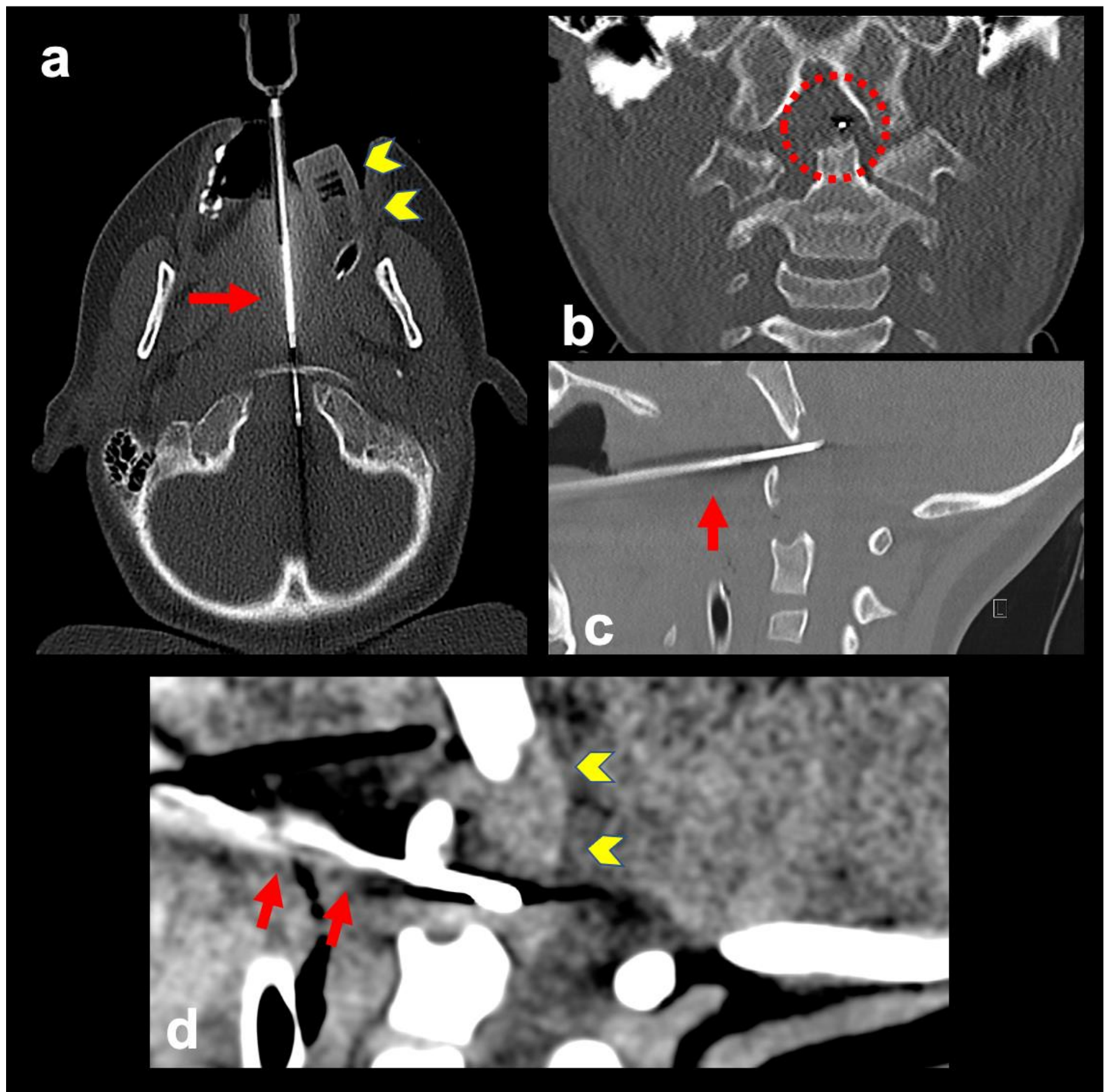

Figure 2: 5 year old female with poorly differentiated chordoma.

FINDINGS: CT guided transoral biopsy of a poorly differentiated chordoma centered at the dens in a 5 years old female patient. (a) Axial unenhanced CT guided biopsy of the C1-C2 mass. The red arrow demonstrates the biopsy needle with $2 \mathrm{~cm}$ throw extended into the mass. The adjacent endotracheal tube is partially visualized (yellow arrowheads) as the procedure was completed under general anesthetic with on call surgeons in house. (b) and (c) (coronal, sagittal reformats respectively) demonstrate accurate CT guided biopsy of the mass. (d) Demonstrates sagittal unenhanced soft tissue reformats with the poorly differentiated chordoma soft tissue mass (yellow arrowheads) and biopsy needle (red arrows) appropriately positioned for tissue sampling. Image (d) was taken from the second biopsy procedure the patient underwent, which was completed using the same technique as the procedure shown in Figures 2(a) - 2(c).

TECHNIQUE: (A,B,C) Siemens CT non-contrast SOMATOM Definition FLASH. Slice thickness $=2 \mathrm{~mm}$. $\mathrm{kVp}=80$, Tube current $=142 \mathrm{~mA}$. Convolution Kernel: bone I70h/2. Gantry tilt = 0. (D): CT non-contrast SOMATOM Definition FLASH. Slice thickness $=1 \mathrm{~mm} . \mathrm{kVp}=100$, Tube current $=49 \mathrm{~mA}$. Convolution Kernel: bone I31s $/ 2$. Gantry tilt $=0$. 


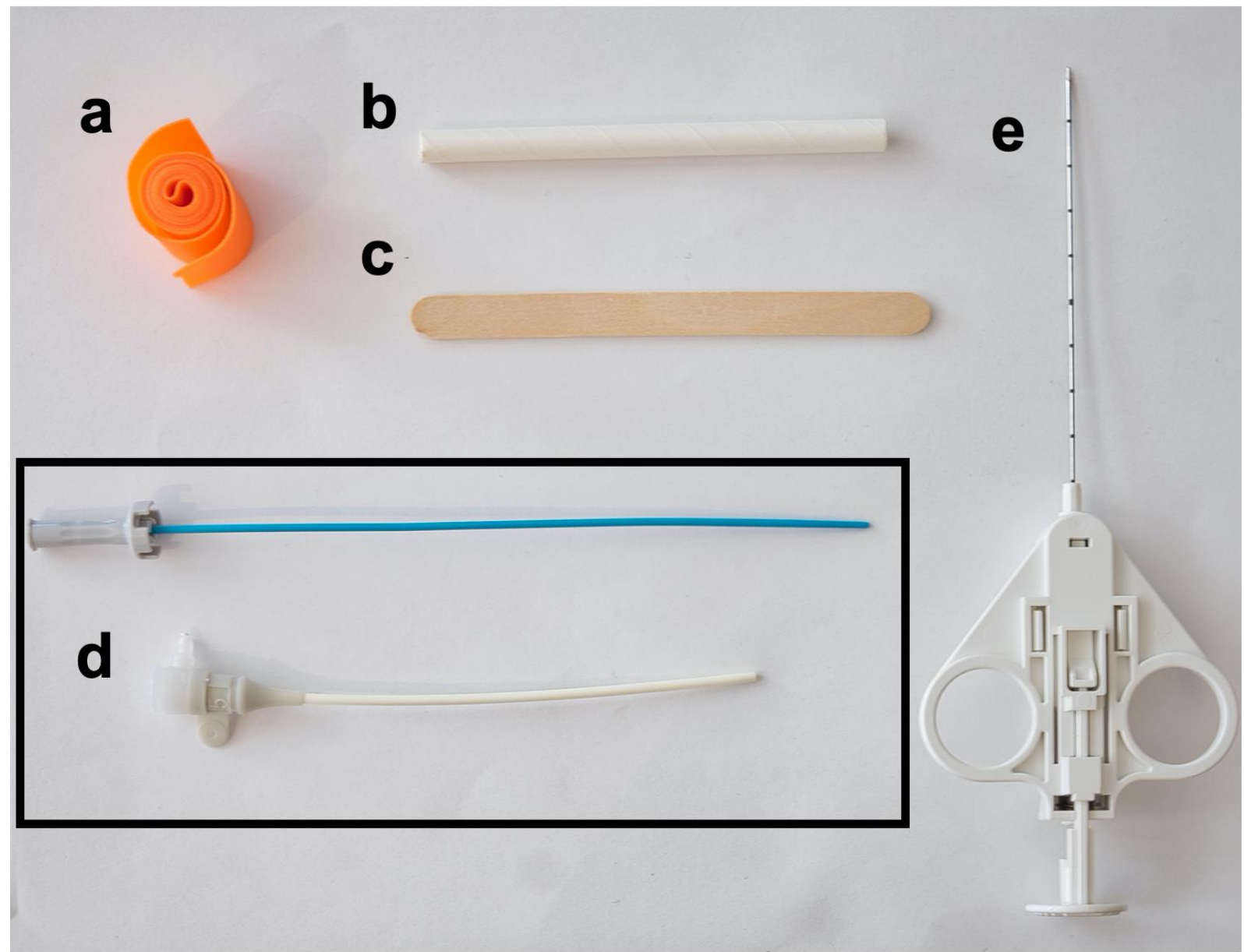

Figure 3: 5 year old female with poorly differentiated chordoma.

Equipment used for a transoral biopsy of a poorly differentiated chordoma centered at the dens in a 5 years old female patient. (a) Tourniquet used to secure endotracheal tube. (b) plastic straw cut to length placed in the patients mouth to displace surrounding soft tissues. (c) Tongue depressor (d) 4-French vascular sheath and coaxial dilator (Pinnacle®; Terumo, Somerset, NJ, USA) used for stable purchase of the biopsy needle (e) 18-gauge $9 \mathrm{~cm}$ long semiautomatic side-cut needle with a $2 \mathrm{~cm}$ throw length (Quick Core®; Cook Medical, Bloomington, IN, USA) biopsy system was advanced in a coaxial fashion through the vascular sheath.

\begin{tabular}{|l|l|}
\hline Etiology & $\begin{array}{l}\text { - The poorly differentiated chordoma is a rare subtype of chordoma, a primary malignancy from } \\
\text { notochord remnants arising from bone. }\end{array}$ \\
\hline Incidence & $\begin{array}{l}\text { - True incidence unknown. } \\
\text { - Classical chordoma accounts for approximately 4\% of primary bone tumours and the poorly } \\
\text { differentiated subtype has only been recognized in recent years. }\end{array}$ \\
\hline Gender Ratio & $\begin{array}{l}\text { - Chordoma classical type has a slight male predominance. } \\
\text { - The poorly differentiated subtype has an unknown gender ratio. }\end{array}$ \\
\hline Age Predilection & $\begin{array}{l}\text { - The classical skull base chordoma appears most frequently in adults (20-40 years). } \\
\text { - The poorly differentiated subtype may have a predilection for the pediatric population. }\end{array}$ \\
\hline Risk factors & - No known risk factors. \\
\hline Treatment & $\begin{array}{l}\text { - Traditionally, surgical excision is first line treatment for chordoma. } \\
\text { - Some literature reports percutaneous radiofrequency ablation or external beam radiotherapy. }\end{array}$ \\
\hline Prognosis & $\begin{array}{l}\text { - Poor. Poorly differentiated subtype of chordoma is more aggressive with a tendency to metastasize. } \\
\text { - Our patient passed away due to complications of lung metastasis. }\end{array}$ \\
\hline Imaging Findings & $\begin{array}{l}\text { - Centered at the skull base most commonly. } \\
\text { - CT: Usually lytic and destructive lesion arising from bone, with surrounding soft tissue component. } \\
\text { - MRI: Infiltrative, non-enhancing, of uniform intermediate to low signal intensity on T1 and T2 } \\
\text { weighted imaging. }\end{array}$ \\
\hline
\end{tabular}

Table 1: Summary table of poorly differentiated chordoma. 


\begin{tabular}{|c|c|c|c|}
\hline $\begin{array}{l}\text { Differential } \\
\text { Diagnosis }\end{array}$ & Radiograph & CT & MRI \\
\hline $\begin{array}{l}\text { Poorly } \\
\text { differentiated } \\
\text { chordoma }\end{array}$ & $\begin{array}{l}\text { Poorly visualized. May } \\
\text { be lytic, destructive } \\
\text { bone-based lesion. }\end{array}$ & $\begin{array}{l}\text { - Variable. Usually lytic and destructive } \\
\text { bone-based lesion, with surrounding soft } \\
\text { tissue component. } \\
\text { - Enhancement pattern: Soft tissue } \\
\text { component may or may not enhance. }\end{array}$ & $\begin{array}{l}\text { - T1: iso-hypointense } \\
\text { - T2: iso-hypointense (to } \\
\text { muscle) } \\
\text { - Enhancement pattern: variable. } \\
\text { No significant enhancement } \\
\text { was appreciated in our case. }\end{array}$ \\
\hline $\begin{array}{l}\text { Classical } \\
\text { chordoma }\end{array}$ & $\begin{array}{l}\text { Poorly visualized. } \\
\text { Expansile, lobulated } \\
\text { lytic bone-based lesion. }\end{array}$ & $\begin{array}{l}\text { - Bone based lytic mass usually at the skull } \\
\text { base or sacrum. Expansile soft tissue } \\
\text { mass. Heterogeneous in their attenuation } \\
\text { due to interspersing of tumor tissue } \\
\text { (isoattenuating) and myxoid cyst or } \\
\text { necrotic degeneration (hypoattenuating). } \\
\text { Hyperattenuation may correspond to bony } \\
\text { sequestration from destruction of bone } \\
\text { rather than tumoral calcification. } \\
\text { - Enhancement pattern: variable. }\end{array}$ & $\begin{array}{l}\text { - T1: iso-hypointense. } \\
\text { - T2: usually hyperintense with } \\
\text { a lobulated appearance } \\
\text { characterized by multiple } \\
\text { hypointense septae. } \\
\text { - Enhancement pattern: } \\
\text { Heterogeneous enhancement } \\
\text { with a honeycomb appearance } \\
\text { of septa. }\end{array}$ \\
\hline $\begin{array}{l}\text { Benign } \\
\text { notochordal cell } \\
\text { tumors }\end{array}$ & $\begin{array}{l}\text { Usually not seen. May } \\
\text { present as a sclerotic } \\
\text { medullary based lesion. }\end{array}$ & $\begin{array}{l}\text { - May be occult on imaging. } \\
\text { - Mild to marked sclerosis, usually a } \\
\text { vertebral body. } \\
\text { - Enhancement pattern: no enhancement. }\end{array}$ & $\begin{array}{l}\text { - Low T1 and high T2 signal. } \\
\text { - Enhancement pattern: no } \\
\text { enhancement. }\end{array}$ \\
\hline $\begin{array}{l}\text { Ecchordosis } \\
\text { physaliphora }\end{array}$ & Poorly visualized. & $\begin{array}{l}\text { - Not well seen. May be a well } \\
\text { circumscribed lytic or exophytic lesion at } \\
\text { the dorsal clivus. } \\
\text { - Enhancement pattern: no enhancement. }\end{array}$ & $\begin{array}{l}\text { - A bony stalk projecting from } \\
\text { the clivus to the retroclival } \\
\text { region is characteristic. Low } \\
\text { T1 and high T2 signal. } \\
\text { - Enhancement pattern: no } \\
\text { enhancement }\end{array}$ \\
\hline Chondrosarcoma & $\begin{array}{l}\text { Mixed sclerotic and } \\
\text { lytic. Chondroid "rings } \\
\text { and arcs" matrix. May } \\
\text { have aggressive } \\
\text { features. Expansile with } \\
\text { periosteal reaction and } \\
\text { soft tissue component. }\end{array}$ & $\begin{array}{l}\text { - Aggressive, lytic and expansile mass with } \\
\text { endosteal scalloping, and soft tissue } \\
\text { component. internal "rings and arcs" } \\
\text { mineralization. } \\
\text { - Enhancement pattern: heterogenous } \\
\text { enhancement. }\end{array}$ & $\begin{array}{l}\text { - heterogenous low } \mathrm{T} 1 \text { and } \\
\text { regions of iso-to-high } \mathrm{T} 2 \\
\text { signal. } \\
\text { - Enhancement pattern: } \\
\text { heterogenous to marked. }\end{array}$ \\
\hline Metastasis & $\begin{array}{l}\text { Poorly characterized. } \\
\text { Variable in appearance, } \\
\text { lytic to sclerotic. }\end{array}$ & $\begin{array}{l}\text { - Variable. May be lytic or sclerotic. } \\
\text { - Enhancement characteristics: Variable }\end{array}$ & $\begin{array}{l}\text { - T1: usually hypo to iso- } \\
\text { intense. } \\
\text { - T2: Usually T2 hyperintense } \\
\text { relative to normal bone } \\
\text { - Enhancement pattern: variable }\end{array}$ \\
\hline
\end{tabular}

Table 2: Differential diagnosis table for bony skull base lesions in a pediatric patient.

\section{ABBREVIATIONS}

$\mathrm{CT}=$ Computed Tomography

MRI = Magnetic Resonance Imaging

TSE $=$ Turbo Spin Echo

\section{KEYWORDS}

Poorly differentiated chordoma; pediatric; spine; CT guided; transoral

\section{Online access}

This publication is online available at:

www.radiologycases.com/index.php/radiologycases/article/view/4208

\section{Peer discussion}

Discuss this manuscript in our protected discussion forum at: www.radiolopolis.com/forums/JRCR

\section{Interactivity}

This publication is available as an interactive article with scroll, window/level, magnify and more features.

Available online at www.RadiologyCases.com

Published by EduRad

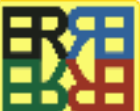

www.EduRad.org 